CLINICAL STUDY

\title{
Growth hormone treatment before the age of 4 years prevents short stature in young girls with Turner syndrome
}

\author{
A Linglart, S Cabrol ${ }^{1}$, P Berlier ${ }^{2}$, C Stuckens ${ }^{3}, \mathrm{~K} \mathrm{Wagner}^{4}$, M de Kerdanet ${ }^{5}$, C Limoni ${ }^{6}$, J-C Carel ${ }^{7}$, J-L Chaussain \\ and French Collaborative Young Turner Study Group \\ Groupe Hospitalier Cochin/Saint-Vincent-de-Paul (APHP), INSERM U561, 82 Avenue Denfert Rochereau, 75674 Paris Cedex 14, France, ${ }^{1}$ Hôpital \\ Armand Trousseau (APHP), 75571 Paris, Cedex 12, France, ${ }^{2}$ Hôpital Femme-mère-enfant, Lyon-Bron, 69677 Bron Cedex, France, ${ }^{3}$ Hôpital Jeanne de \\ Flandre, 59037 Lille, France, ${ }^{4}$ Hôpital de l'Archet II, 06202 Nice, Cedex 3, France, ${ }^{5}$ Hôpital Sud, 35200 Rennes, France, ${ }^{6}$ University of Applied Sciences \\ of Southern Switzerland, Lugano, CH-6928 Switzerland and ${ }^{7}$ Hôpital Robert Debré, 75019 Paris, France
}

(Correspondence should be addressed to A Linglart; Email: agnes.linglart@inserm.fr)

\begin{abstract}
Objective: Adult height deficit seen in Turner syndrome (TS) originates, in part, from growth retardation in utero and throughout the first 3 years of life. Earlier diagnosis enables earlier therapeutic intervention, such as with recombinant human GH (r-hGH), which may help to prevent growth retardation. In this open-label, multicentre phase III study, we investigated efficacy and safety in r-hGH treatment in young girls with TS.

Subjects and methods: Girls $(n=61)$ aged $<4$ years with TS receiving $0.035-0.05 \mathrm{mg} / \mathrm{kg}$ per day r-hGH for 4 years were compared with an historical control group $(n=51)$ comprising untreated, age- and height-matched girls with TS. The main outcome measure was change in height SDS (H-SDS). Other measures included changes in height velocity SDS, IGF1 levels and glucose metabolism.

Results: After 4 years, a gain in mean H-SDS of 1.0 SDS (from $-2.33 \pm 0.73$ to $-1.35 \pm 0.86$ SDS) was observed with r-hGH treatment, in contrast to the decrease in mean H-SDS of 0.3 SDS in the control group (from $-2.09 \pm 0.81$ to $-2.44 \pm 0.73$ SDS; $P<0.0001$ ). $r$-hGH treatment was the main predictor of H-SDS gain and accounted for $52 \%$ of variability (multivariate analysis). r-hGH was well tolerated. As expected, IGF1 levels rose with treatment. A case of transient glucose intolerance resolved after dietary adaptation.

Conclusion: Early treatment with r-hGH helps to prevent natural evolution towards short stature in most girls with TS. IGF1 levels and glucose metabolism should be monitored routinely during r-hGH therapy.
\end{abstract}

European Journal of Endocrinology 164 891-897

\section{Introduction}

It is estimated that one in every 2500 live-birth girls is affected by Turner syndrome (TS) (1). Girls with TS carry an abnormal or missing X chromosome in some or all of their cells and have a range of different phenotypes including lymphoedema, webbing of the neck, cardiac abnormalities and gonadal dysgenesis $(1,2)$. The most common feature of TS is short stature, which occurs as a result of growth retardation before birth, throughout childhood and during adolescence $(1,3)$. Of the 2.0-3.0 s.D. height deficit seen in girls with TS, longitudinal studies have estimated that 0.7-1.2 s.D. are lost before birth and 1.3-1.8 S.D. are lost in the first 3 years of life $(4,5)$.

Recombinant human GH (r-hGH) treatment increases growth in girls with TS $(6,7)$, with a final adult height gain of about $6 \mathrm{~cm}(8)$. Important factors associated with adult height are age at onset of treatment (negative association) and the duration of treatment (positive association), raising the question of earlier intervention with $\mathrm{GH}$ in this patient population (9-11). Therefore, it may be possible to realise the maximal therapeutic benefits of r-hGH in girls with TS by initiating treatment during the first few years of life. Until recently, studies investigating $\mathrm{r}$-hGH treatment in TS have not included girls under the age of 4 years, perhaps, in part, because of delayed diagnosis of TS (7). However, in the past decade, guidance on the diagnosis of TS has improved $(12,13)$, leading to a rise in the number of girls being diagnosed with TS at an earlier age (14). Recent studies have shown that early treatment with $\mathrm{GH}$ of infants and toddlers with TS improves growth $(15,16)$.

This study was conducted to evaluate the efficacy and safety of r-hGH treatment in girls with TS under the age of 4 years. After 4 years of treatment, height in these girls was compared with an historical control group of untreated girls with TS, matched for age and height at baseline. 


\section{Subjects and methods}

A total of 64 girls with TS, aged $<4$ years born between 1988 and 1995 (median 1991) and with a height at least 1 SDS below the general population standard $(17,18)$, were enrolled at 24 centres in France between 1992 and 1997. Girls with any form of TS-associated $\mathrm{X}$-chromosome abnormality were included in the study. Girls were excluded if they were found to have abnormal glucose metabolism, were GH deficient, had other medical conditions (e.g. renal deficiencies or cardiac dysfunction) or were receiving concomitant medications that could interfere with their growth (e.g. steroids). Written informed consent was given by the parent(s)/guardian(s) of each girl prior to entry to the study. The study was conducted in accordance with the Declaration of Helsinki and the principles of Good Clinical Practice and was approved by the Paris Cochin (CCPPRB) ethics committee.

Longitudinal assessment was conducted on an historical group of 51 untreated control girls with TS born between 1961 and 1990 (median 1978) collected by $\mathrm{SC}$ for comparison with individuals receiving $\mathrm{r}-\mathrm{hGH}$ treatment. Selection criteria for the control group were TS assessed by the karyotype, known target height, known birth height and weight, known final height, highest period between height measurements of 6 months and height below -1 s.D. relative to the general population standard. These untreated girls were matched to the treated group by age and height at baseline (within 3 months and $2 \mathrm{~cm}$ respectively) and followed in the same centre. Birth weight, birth length and parental height were recorded and their height was measured at least once every 6 months.

\section{Study design and interventions}

This was a multicentre, open-label, phase III study (Merck Serono study 5834, NCT01066052). After inclusion, all girls received r-hGH (Saizen, Merck Serono S.A., an affiliate of Merck KGaA) as a subcutaneous injection administered by a parent in the evening. During years $1-2$, the dose of r-hGH received by the girls depended on their baseline height SDS (H-SDS) relative to the general population standard $(17,18)$; girls with an $\mathrm{H}-\mathrm{SDS}$ of -2 S.D. or lower received $0.05 \mathrm{mg} / \mathrm{kg}$ per day $\mathrm{r}$-hGH (the standard dose licensed for TS in France) and those with an H-SDS between -1 and -2 S.D. received $0.035 \mathrm{mg} / \mathrm{kg}$ per day r-hGH. After 2 years of treatment, all girls received a fixed dose of $0.05 \mathrm{mg} / \mathrm{kg}$ per day for a further 2 years.

\section{Assessments}

The primary outcome measure in this study was change in H-SDS from baseline to 4 years. Clinical examinations were conducted at baseline and every 3 months during the study. At each visit, height was measured using a stadiometer, by the same investigator on each occasion.
Changes in auxological parameters (H-SDS, height velocity SDS (HV-SDS)) were compared with published growth standards for general and TS populations $(17,18)$. Blood pressure was measured and the nature and incidence of adverse events (AEs) were recorded at each visit.

At baseline and every 6 months throughout the first 2 years of treatment, laboratory tests were conducted (haematology, blood glucose metabolism and levels of insulin-like growth factor 1 (IGF1) and bone age (BV) was assessed. Changes in glucose metabolism were monitored by measuring blood glucose concentration, $\mathrm{HbA1c}$ levels and an oral glucose tolerance test every 2 years. Samples for IGF1 levels were taken during the first and second years of the study and were analysed at the end of the study in a central laboratory. After extraction, IGF1 levels were measured by RIA using a polyclonal anti IGF1 antibody (19). Thyroid function was assessed at baseline and at 6,12 and 24 months. The production of antibodies to $\mathrm{r}-\mathrm{hGH}$ was monitored at baseline and at 3, 6, 12 and 24 months, measured in a central laboratory using ELISA.

During the following 2 years, the treated girls continued to receive r-hGH. Assessments of blood glucose $(\mathrm{HbA} 1 \mathrm{c})$ and IGF1 levels, liver function (transaminases and $\gamma$-glutamyl transpeptidase) and BV were recommended annually and performed at the discretion of the investigator.

\section{Statistical methods}

All girls receiving at least one dose of treatment were included in the efficacy and safety analyses (intentto-treat population). The difference between treated and control groups was analysed using Student's $t$-test, and differences between standard dose and lower dose groups were analysed using unpaired $t$-test. All statistical tests were two sided and performed at the $5 \%$ level of significance. Multivariate analysis of the determinant(s) of H-SDS gain was conducted and included terms for age, H-SDS and HV-SDS (TS standard) at baseline, study cohort, birth length SDS, parental H-SDS (general population standard) and karyotype. Because of the small numbers of girls in each dose group, this multivariate analysis was not corrected for dose. The primary objective of the study was to compare the height of girls who had received r-hGH treatment for 4 years against the control group of untreated girls with TS, matched for age and height at baseline.

\section{Results}

\section{Patients}

Of the 64 girls with TS who were enrolled in the study, 61 received r-hGH treatment for 4 years and completed the study. During years 1-2, 43 girls received 
Table 1 Baseline demographics and karyotype data for study participants. Results are expressed as mean \pm s.D. Standard-dose group $=0.05 \mathrm{mg} / \mathrm{kg}$ per day; low-dose group $=0.035 \mathrm{mg} / \mathrm{kg}$ per day Target height SDS $=$ (maternal height SDS + paternal height SDS)/2.

\begin{tabular}{lccc}
\hline & $\begin{array}{c}\text { Standard- } \\
\text { dose group } \\
(n=43)\end{array}$ & $\begin{array}{c}\text { Low-dose } \\
\text { group } \\
(n=18)\end{array}$ & $\begin{array}{c}\text { Control } \\
\text { group } \\
(n=51)\end{array}$ \\
\hline Age (range) (years) & $2.6 \pm 0.6$ & $2.6 \pm 1.3$ & $2.6 \pm 1.0$ \\
& $(0.6-4.1)$ & $(1.3-3.8)$ & $(0.5-4.0)$ \\
Birth weight SDS & $-1.4 \pm 1.1$ & $-1.0 \pm 0.5$ & $-1.3 \pm 0.9$ \\
Birth length SDS & $-2.4 \pm 1.0$ & $-1.85 \pm 0.8$ & $-1.9 \pm 1.1$ \\
Height SDS & & & \\
GP standard & $-2.6 \pm 0.6$ & $-1.6 \pm 0.4$ & $-2.1 \pm 0.8$ \\
$\quad$ TS standard & $-0.7 \pm 0.7$ & $0.2 \pm 0.4$ & $-0.2 \pm 0.8$ \\
Target height SDS & $-0.3 \pm 0.9$ & $0.4 \pm 0.7^{\star}$ & $-0.6 \pm 0.9$ \\
Karyotypes $(n)$ & & & \\
$45, X$ & 25 & 14 & 23 \\
$45, X / 46, X X$ & 5 & 1 & 7 \\
$45, X / 46, X i s o X q$ & 6 & 1 & 4 \\
Others & 6 & 2 & 17 \\
\hline
\end{tabular}

${ }^{*} P<0.0001$ versus control group. GP, general population.

$0.035 \mathrm{mg} / \mathrm{kg}$ per day $\mathrm{r}-\mathrm{hGH}$ and 18 girls received $0.05 \mathrm{mg} / \mathrm{kg}$ per day $\mathrm{r}-\mathrm{hGH}$. A total of 200 girls were screened in the control group and only 51 of these were matched to girls in the treated group according to age and height at baseline. Baseline demographic characteristics were similar for girls treated with r-hGH and those in the control group (Table 1), except that, as expected, girls with a baseline H-SDS above -2 had a significantly higher target H-SDS. There were no significant differences in karyotype distribution in both the groups. Girls included in the study had a mean height typical of girls with TS at this age (18). There was no significant difference in the mean \pm s.D. age of girls who received $0.035 \mathrm{mg} / \mathrm{kg}$ per day $\mathrm{r}-\mathrm{hGH}$ and those who received $0.05 \mathrm{mg} / \mathrm{kg}$ per day r-hGH (Table 1).

\section{Height and growth velocity}

After 4 years of treatment, a significant gain in mean H-SDS relative to the general population of about 1.0 SDS (from $-2.33 \pm 0.73$ to $-1.35 \pm 0.86$ SDS) was observed in the r-hGH-treated group. This contrasts with the decrease in mean H-SDS of about 0.3 SDS observed in the control group (from $-2.09 \pm 0.81$ to $-2.44 \pm 0.73$ SDS; $P<0.0001$ versus treated group; Fig. 1a). Thus, the between-group mean difference in height SDS after treatment was $1.09 \pm 0.80$. This effect was reflected by a significant increase in mean HV-SDS, relative to the general population, in the treated group (increase of 0.8 SDS from $-1.22 \pm 1.57$ to -0.44 \pm 1.35 ), compared with the control group (increase of 0.3 SDS from $-1.38 \pm 0.84$ to $-1.13 \pm 1.31$; $P<0.001$ versus treated group; Fig. 1c). Figure 1 also shows the results when the girls were grouped by their GH dose during years 1-2.
Most or all of this gain in H-SDS occurred during the first 2 years of the study and, during this period, girls receiving the standard dose of r-hGH showed a significantly greater increase in mean H-SDS (general population standard) than those who received the low dose of $\mathrm{r}-\mathrm{hGH}(1.05 \pm 0.49$ vs $0.62 \pm 0.29$ respectively; $P=0.0009$ ).

After 4 years, 49 girls $(80.3 \%)$ in the group receiving $\mathrm{r}$-hGH had maintained or reached a normal height (i.e. a height within -2 SDS of the general
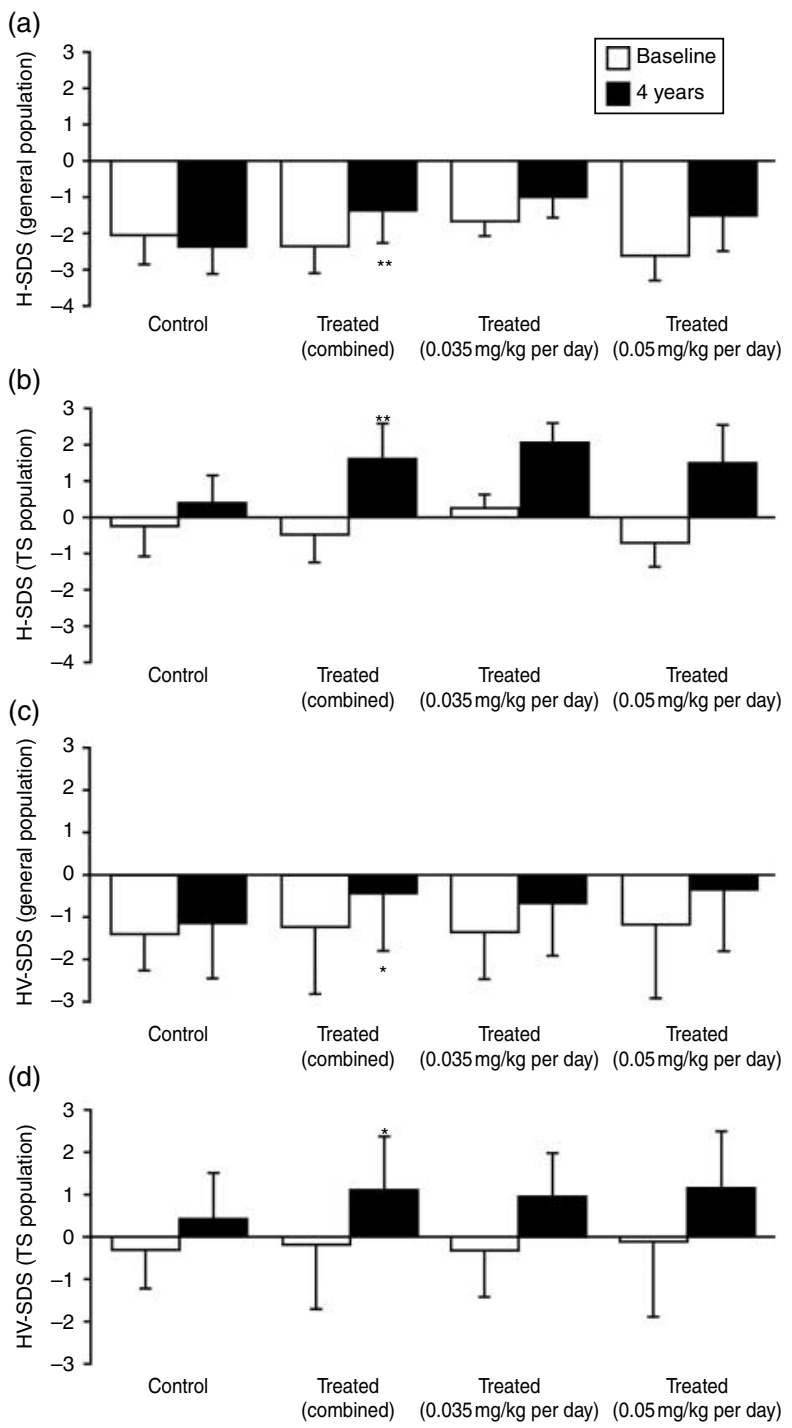

Figure 1 Auxological parameters in young girls with Turner syndrome (TS) treated with recombinant human $\mathrm{GH}$ and untreated (control) girls with TS, at baseline and after 4 years. The four graphs show mean (with s.D. error bar) for all girls in the study (combined, $n=61)$ and by the two doses $(0.035 \mathrm{mg} / \mathrm{kg}$ per day, $n=43$ and $0.05 \mathrm{mg} / \mathrm{kg}$ per day, $n=18$ ). Changes in height SDS (H-SDS) are referenced against (a) the general population (17) and (b) the TS population (18) and changes in HV-SDS are referenced against (c) the general population (17) and (d) the TS population (18). ${ }^{\star} P<0.001$ versus control group; ${ }^{\star} P<0.0001$ versus control group. 


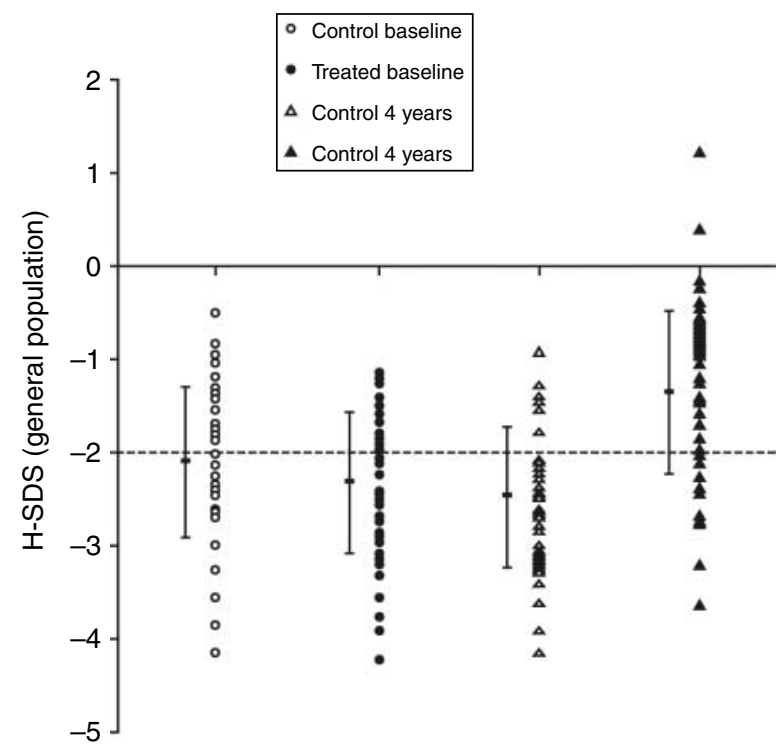

Figure 2 Height SDS (H-SDS; general population standard) for girls with Turner syndrome treated with recombinant human $\mathrm{GH}(n=61)$ and untreated controls $(n=51)$. Values are shown as both mean (s.D.) and individual H-SDS.

population standard), whereas 38 girls (74.5\%) in the control group still had short stature (i.e. a height of -2 SDS or lower, relative to the general population standard; Fig. 2).

Relative to the general TS population, girls with TS treated with r-hGH showed an improvement in H-SDS (Fig. 1b) and HV-SDS (Fig. 1d) compared with untreated girls, as had been expected. Specifically, these results showed a significant gain in mean H-SDS of about 2 SDS (from $-0.42 \pm 0.74$ to $1.64 \pm 0.94$ SDS) in the r-hGHtreated group compared with about 0.7 SDS in the control group (from $-0.21 \pm 0.80$ to $0.44 \pm 0.74$ SDS; $P<0.0001)$ and a significant increase in mean HV-SDS in the treated group (gain of 1.3 SDS from $-0.16 \pm 1.58$ to $1.11 \pm 1.23$ SDS) compared with the control group (gain of 0.7 SDS from $-0.29 \pm 0.88$ to $0.44 \pm 1.08$ SDS; $P<0.001$ ).

Multivariate analysis showed that the main predictor of H-SDS gain (TS population standard) was whether girls had received $\mathrm{r}$-hGH treatment (this accounted for $52 \%$ of variability; Table 2 ). There were two additional factors that had a significant effect on H-SDS gain: H-SDS at baseline (4.5\%) and maternal H-SDS (3.3\%). Age was not a predictor of H-SDS gain in this young cohort.

\section{Bone age}

At baseline, the mean \pm s.D. value for $\mathrm{BV}$ minus chronological age $(\mathrm{BA}-\mathrm{CA})$ among the girls who received $\mathrm{r}-\mathrm{hGH}$ was $-8.9 \pm 7.5$ months $(n=58)$. After 1 year of $\mathrm{r}-\mathrm{hGH}$ treatment, $\mathrm{BA}-\mathrm{CA}$ was unchanged $(-8.7 \pm 6.5$ months, $n=60, P=0.787)$, and after 2 years of treatment, BA-CA was still not significantly different from baseline $(-8.1 \pm 7.8$ months, $n=57$, $P=0.450)$. Data on $\mathrm{BV}$ were not recorded for girls in the control cohort.

\section{Safety}

A total of 236 AEs occurred among 47 girls during the study. None was considered related to the study treatment. The most frequent AEs were infectious diseases (213/236, 90.3\% of AEs), which are common in girls of this age. Gastrointestinal disorders constituted ten AEs $(10 / 236,4.2 \%)$. Among those, eight AEs were considered to be of a serious nature: seven occurred in the low-dose group (urethral reflux corrected by surgery; trauma leading to scalp surgery; measles, serious otitis and IgG g4 deficiency; arterial hypertension; chronic persistent cytolysis; surgical procedure to remove a large mass thought to be a meningocele or a benign cyst; placement of a transtympanic drainage tube) and one occurred in the standarddose group (tonsillectomy/adenoidectomy). All serious AEs resolved.

Carbohydrate metabolism was normal in all but one girl receiving $\mathrm{r}-\mathrm{hGH}$ (mean \pm s.D. HbAlc (\%) among treated girls: $4.70 \pm 0.87$ at baseline, $4.87 \pm 0.87$ after 2 years). This girl, in the low-dose group, experienced transient glucose intolerance after 6 months of treatment (normal fasting glucose level, HbA1c= $8.6 \%$ ), which was resolved by a change in diet (normal fasting glucose level, normal $\mathrm{HbA} 1 \mathrm{c}$ at 18 months of treatment).

Mean IGF1 levels at baseline were within the normal ranges; levels rose significantly during the first 6 months

Table 2 Predictors of gain in height (SDS, TS population standard) between months 0 and 48 of the study in young girls with TS, assessed by multivariate analysis. Other tested variables, HV-SDS (TS standard) at baseline, paternal height SDS (general population), birth length SDS, karyotype and age at baseline were not predictive of gain in height.

\begin{tabular}{lcccr}
\hline Variable & $\begin{array}{c}\text { Variability } \\
(\%)\end{array}$ & $\begin{array}{c}\text { Regression } \\
\text { coefficient }\end{array}$ & $\begin{array}{c}\text { 95\% confidence } \\
\text { interval }\end{array}$ & $\boldsymbol{P}$ value \\
\hline Constant & - & 0.9929 & $0.316,1.670$ & 0.005 \\
Height SDS (TS standard) at baseline & 4.5 & -0.3700 & $-0.574,-0.167$ & 0.001 \\
Maternal height SDS (general population) & 3.5 & 0.1625 & $0.021,0.304$ & 0.025 \\
Whether r-hGH treatment was given & 52.0 & 1.3468 & $1.046,1.648$ & $<0.001$
\end{tabular}

$\mathrm{HV}$, height velocity; r-hGH, recombinant human $\mathrm{GH}$; TS, Turner syndrome. 


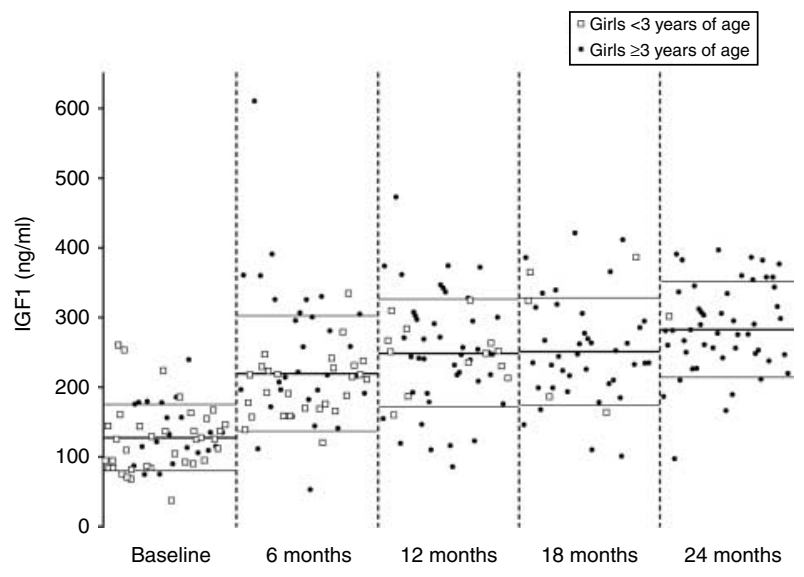

Figure 3 Changes in IGF1 levels among girls with Turner syndrome treated over 2 years with recombinant human GH. Normal IGF1 ranges were $45-117 \mathrm{ng} / \mathrm{ml}$ for girls aged $<3$ years and 80 $236 \mathrm{ng} / \mathrm{ml}$ for girls aged 3-6 years. NB: IGF1 samples from years 1 and 2 of the study only were analysed by the central laboratory. Bar shows mean (S.D.) IGF1 levels.

of treatment and did not change significantly thereafter (Fig. 3). During the first 24 months of r-hGH treatment, IGF1 levels were similar in both the groups. At 24 months, girls treated with the lower dose of r-hGH had significantly lower IGF1 levels than those treated with the higher dose $(223 \pm 58$ and $280 \pm 67 \mathrm{ng} / \mathrm{ml}$ respectively; $P=0.004)$. About $75 \%(46 / 61)$ of the treated girls experienced elevated IGF1 values $(>2$ SDS for age). Other parameters (blood pressure, haematology, anti-hGH antibodies and thyroid activity) did not differ significantly between groups and remained within normal levels throughout the study.

\section{Discussion}

The results of this study have shown that $\mathrm{r}-\mathrm{hGH}$ treatment initiated before 4 years of age significantly increases growth in girls with TS compared with the historical control group, helping to prevent the natural trend towards short stature shown by untreated girls with this disorder. This study specifically focused on the initiation of r-hGH treatment in early childhood, during the years when growth rate is most affected by the disease $(4,5)$.

In this study, $80 \%$ of the 61 girls receiving 4 years of treatment with r-hGH were able to attain a normal height by a mean age of 6.6 years. After 4 years of treatment, girls were 1.09 s.D. higher than untreated girls relative to the general population. Previous studies in which treatment was started at an older age $(\sim 8-12$ years) have reported similar gains in height, ranging from 0.8 to 2.1 SDS (20-23). Several studies have examined whether earlier age at r-hGH initiation leads to a better therapeutic outcome in girls with TS. Although one study found no effect (24), other studies have concluded that earlier treatment leads to greater height gains $(9,11,25-27)$. However, one limitation of these approaches is that the data derive from girls with a mean age at start of treatment ranging from 7 to 13 years and cannot be extrapolated to the young age group studied here.

To our knowledge, this study examines the effects of r-hGH treatment in one of the youngest cohorts of girls with TS to be assessed to date. In girls with TS, the duration of GH therapy prior to oestrogen initiation is a strong predictor of adult height $(28,29)$. The potential benefits of early treatment with r-hGH in young girls with TS have been investigated by two studies, which includes one randomised study. The r-hGH treatment resulted, in 29 girls with TS under the age of 6 years, in a mean \pm s.D. H-SDS improvement of $1.46 \pm 0.88$ (16) and, in 88 girls aged between 9 months and 4 years, in a gain of $1.6 \pm 0.6$ in H-SDS (15). Our study, in a group of 61 young girls with TS over 4 years of treatment, thus confirms the finding that early treatment is effective in girls with TS for the prevention of growth retardation. We also add to these results by showing that treatment with $\mathrm{r}$-hGH increased H-SDS in girls with a normal height at study entry (the lower dose group). However, it will be essential to analyse adult heights in this group, all of whom will be older than 17 years in 2012 .

In this study, multivariate analysis revealed that baseline H-SDS had a negative effect on H-SDS gain observed with r-hGH treatment. A number of other studies investigating the use of GH therapy in girls with TS have reported that treatment has a greater effect on growth in shorter girls than it does in girls with a smaller height deficit before treatment $(22,25,30)$. In this study, girls with greater height at baseline grew less than those with a shorter height; this may be explained by the dose of r-hGH used, depending on the height of the girl at entry to the study.

Overall, r-hGH was well tolerated, with the most common AEs being common childhood infections that were considered as unrelated to the study treatment. Girls with TS have an increased risk of glucose metabolism abnormalities (relative risk (RR) of type 1 diabetes: 11.6, 95\% confidence interval (CI): 5.3-22.0; RR of type 2 diabetes: 4.4, 95\% CI: 2.4-7.7) (1). Furthermore, it is generally accepted that GH therapy induces insulin resistance in girls with TS (1), an effect that is reversible with discontinuation of treatment (31). In our study, we observed one episode of transient glucose intolerance in a girl receiving $\mathrm{r}-\mathrm{hGH}$, and this was resolved by dietary adaptation. It is not yet clear whether the increased risk of insulin resistance associated with GH therapy translates to an increased glycaemic risk with long-term treatment. In one study that evaluated 47 girls with TS, treatment with r-hGH $(0.05 \mathrm{mg} / \mathrm{kg}$ per day) over 6 years led to a significant increase in fasting insulinaemia, but did not significantly increase the risk of impaired glucose tolerance or type 2 diabetes mellitus (32). 
We observed an increase in IGF1 levels during the first 6 months of r-hGH treatment, which remained elevated for the rest of the study. Similarly, Massa et al. (1992) (33) have reported that IGF1 levels increase rapidly during the first few months of treatment and then reach a plateau. Unfortunately, in this study, due to the centralised analyses of IGF1 dosage at the end of the study, no action was taken to monitor the treatment according to the IGF1 level. This differs clearly from the current standard of r-hGH treatment.

This study had a number of limitations, which should be considered. First, there was no dose correction in the multivariate analysis; a dose correction may have allowed a better assessment of treatment effect. Secondly, despite our matching strategy, the study group and the historical control group might differ slightly, introducing bias in the analysis (for example the early diagnosis of TS in the study group may reflect a more severe disease than the control group). Thirdly, IGF1 values were only assessed during 2 years. Longerterm data (e.g. at 4 years) would have provided valuable additional information about the effects of r-hGH treatment on the GH-IGF1 axis. The girls received a slightly lower r-hGH dose than was assigned (standard dose: 0.047 instead of $0.05 \mathrm{mg} / \mathrm{kg}$ per day; low dose: 0.033 instead of $0.035 \mathrm{mg} / \mathrm{kg}$ per day), but this was unlikely to impact on the results.

In conclusion, this study has shown that in girls who have TS, treatment with r-hGH during the first years of childhood, when growth retardation is greatest, leads to large and significant increases in height. Overall, our results show that r-hGH has a favourable safety profile in young girls with TS, although careful monitoring of IGF1 levels and glucose metabolism is recommended. GH might be used in girls with low normal height to prevent short stature, yet final height and long-term tolerance data are necessary to issue recommendations from our study.

\section{Declaration of interest}

A Linglart, S Cabrol, C Stuckens, K Wagner, M de Kerdanet, and J-L Chaussain have nothing to disclose that could be perceived as prejudicing the impartiality of the research reported. P Berlier has received an honorarium for a training day from Merck Serono. C Limoni and J-C Carel have received consulting fees from Merck Serono.

\section{Funding}

This study was supported by Merck Serono s.a.s., 37 rue SaintRomain, F- 69379 Lyon Cédex 08, France.

\section{Acknowledgements}

Thiriet provided assistance with study conduct. The authors would like to thank Polly Field and Imogen Horsey of Caudex Medical (supported by Merck Serono S.A., Geneva, Switzerland, an affiliate of Merck KGaA, Darmstadt, Germany) for their assistance with the development of this manuscript.

\section{French Collaborative Young Turner Study Group}

Angers: JM Limal, R Coutant, S Rouleau; Besançon: AM Bertrand; Bordeaux: M Colle; Brest: C Metz; Caen: S Nivot; Clermont-Ferrand: G Malpuech, H Carla; Dunkerque: GA Loeuille; Grenoble: M Bost; Limoges: A Lienhardt; Lorient: C Naud-Saudreau; Lyon-Bron: M Nicolino, M David; Montpellier: C Jeandel; Nancy: B Leheup; Paris R. Debré: P Czernichow, J Léger; Paris Necker: M Polak; Paris SVP: D Gendrel; Reims: V Sulmont; Rouen: C Lecointre; St Etienne: O Richard; Strasbourg: S Soskin; Toulouse: M Tauber, I Oliver.

\section{References}

1 Gravholt $\mathrm{CH}$. Epidemiological, endocrine and metabolic features in Turner syndrome. European Journal of Endocrinology 2004151 657-687. (doi:10.1530/eje.0.1510657)

2 Hjerrild BE, Mortensen KH \& Gravholt $\mathrm{CH}$. Turner syndrome and clinical treatment. British Medical Bulletin $2008 \mathbf{8 6}$ 77-93. (doi:10.1093/bmb/ldn015)

3 Ranke MB \& Grauer ML. Adult height in Turner syndrome: results of a multinational survey 1993. Hormone Research 1994 42 90-94. (doi:10.1159/000184154)

4 Even L, Cohen A, Marbach N, Brand M, Kauli R, Sippell W \& Hochberg Z. Longitudinal analysis of growth over the first 3 years of life in Turner's syndrome. Journal of Pediatrics 2000137 460-464. (doi:10.1067/mpd.2000.109110)

5 Davenport ML, Punyasavatsut N, Stewart PW, Gunther DF, Savendahl L \& Sybert VP. Growth failure in early life: an important manifestation of Turner syndrome. Hormone Research 200257 157-164. (doi:10.1159/000058376)

6 Bondy CA. Care of girls and women with Turner syndrome: a guideline of the Turner Syndrome Study Group. Journal of Clinical Endocrinology and Metabolism 200792 10-25. (doi:10.1210/jc. 2006-1374)

7 McCarthy K \& Bondy CA. Turner syndrome in childhood and adolescence. Expert Review of Endocrinology \& Metabolism 20083 771-775. (doi:10.1586/17446651.3.6.771)

8 Baxter L, Bryant J, Cave CB \& Milne R. Recombinant growth hormone for children and adolescents with Turner syndrome. Cochrane Database of Systematic Reviews, 2007 CD003887. (doi:10. 1002/14651858)

9 Ranke MB, Lindberg A, Ferrandez LA, Darendeliler F, AlbertssonWikland K, Dunger D, Cutfield WS, Tauber M, Wilton P, Wollmann HA \& Reiter EO. Major determinants of height development in Turner syndrome (TS) patients treated with GH: analysis of 987 patients from KIGS. Pediatric Research 200761 105-110. (doi:10.1203/01.pdr.0000250039.42000.c9)

10 Soriano-Guillen L, Coste J, Ecosse E, Leger J, Tauber M, Cabrol S, Nicolino M, Brauner R, Chaussain JL \& Carel JC. Adult height and pubertal growth in Turner syndrome after treatment with recombinant growth hormone. Journal of Clinical Endocrinology and Metabolism 200590 5197-5204. (doi:10.1210/jc.20050470)

11 Ranke MB, Lindberg A, Chatelain P, Wilton P, Cutfield W, Albertsson-Wikland K \& Price DA. Prediction of long-term response to recombinant human growth hormone in Turner syndrome: development and validation of mathematical models. KIGS International Board. Kabi International Growth Study. Journal of Clinical Endocrinology and Metabolism 200085 4212-4218. (doi:10.1210/ jc.85.11.4212)

12 Savendahl L \& Davenport ML. Delayed diagnoses of Turner's syndrome: proposed guidelines for change. Journal of Pediatrics 2000137 455-459. (doi:10.1067/mpd.2000.107390)

13 Saenger P, Wikland KA, Conway GS, Davenport M, Gravholt CH, Hintz R, Hovatta O, Hultcrantz M, Landin-Wilhelmsen K, Lin A, Lippe B, Pasquino AM, Ranke MB, Rosenfeld R \& Silberbach M. 
Recommendations for the diagnosis and management of Turner syndrome. Journal of Clinical Endocrinology and Metabolism 2001 86 3061-3069. (doi:10.1210/jc.86.7.3061)

14 Massa G, Verlinde F, De Schepper J, Thomas M, Bourguignon JP, Craen M, de Zegher F, Francois I, Du Caju M, Maes M \& Heinrichs C. Trends in age at diagnosis of Turner syndrome. Archives of Disease in Childhood 200590 267-268. (doi:10.1136/ adc.2004.049817)

15 Davenport ML, Crowe BJ, Travers SH, Rubin K, Ross JL, Fechner PY, Gunther DF, Liu C, Geffner ME, Thrailkill K, Huseman C, Zagar AJ \& Quigley CA. Growth hormone treatment of early growth failure in toddlers with Turner syndrome: a randomized, controlled, multicenter trial. Journal of Clinical Endocrinology and Metabolism 200792 3406-3416. (doi:10. 1210/jc.2006-2874)

16 Wasniewska M, De Luca F, Bergamaschi R, Guarneri MP, Mazzanti L, Matarazzo P, Petri A, Crisafulli G, Salzano G \& Lombardo F. Early treatment with GH alone in Turner syndrome: prepubertal catch-up growth and waning effect. European Journal of Endocrinology 2004151 567-572. (doi:10.1530/eje. $0.1510567)$

17 Sempé M, Pédron G, Roy-Pernot. Auxologie MP, méthode et séquences. Paris: Theraplix, 1979.

18 Sempé M. Growth curves in untreated female gonadal dysgenesis. French reference data from birth to age 22 years. Annals of Pediatrics (Paris) $1997 \mathbf{4 4} 529-537$.

19 Chatelain PG, Van Wyk J, Copeland KC, Blethen SL \& Underwood LE. Effect of in vitro action of serum proteases or exposure to acid on measurable immunoreactive somatomedin-C in serum. Journal of Clinical Endocrinology and Metabolism 198356 376-383. (doi:10.1210/jcem-56-2-376)

20 Plotnick L, Attie KM, Blethen SL \& Sy JP. Growth hormone treatment of girls with Turner syndrome: the National Cooperative Growth Study experience. Pediatrics $1998 \quad 102$ 479-481. (doi:10.1542/peds.102.2.S1.479)

21 Sas TC, de Muinck Keizer-Schrama SM, Stijnen T, van Teunenbroek A, Hokken-Koelega AC, Waelkens JJ, Massa GG, Vulsma T, Gerver WJ, Reeser HM, Delemarre-van de Waal HE, Jansen M \& Drop SL. Final height in girls with Turner's syndrome treated with once or twice daily growth hormone injections. Dutch Advisory Group on Growth Hormone. Archives of Disease in Childhood 199980 36-41. (doi:10.1136/adc.80.1.36)

22 van Pareren YK, de Muinck Keizer-Schrama SM, Stijnen T, Sas TC, Jansen M, Otten BJ, Hoorweg-Nijman JJ, Vulsma T, StokvisBrantsma WH, Rouwe CW, Reeser HM, Gerver WJ, Gosen JJ, Rongen-Westerlaken C \& Drop SL. Final height in girls with turner syndrome after long-term growth hormone treatment in three dosages and low dose estrogens. Journal of Clinical Endocrinology and Metabolism 2003 88 1119-1125. (doi:10.1210/jc.2002-021171)

23 Rochiccioli P, Battin J, Bertrand AM, Bost M, Cabrol S, Le Bouc Y, Chaussain JL, Chatelain P, Colle M \& Czernichow P. Final height in Turner syndrome patients treated with growth hormone. Hormone Research 199544 172-176. (doi:10.1159/000184620)

24 Massa G, Heinrichs C, Verlinde S, Thomas M, Bourguignon JP, Craen M, Francois I, Du Caju M, Maes M \& De Schepper J. Late or delayed induced or spontaneous puberty in girls with Turner syndrome treated with growth hormone does not affect final height. Journal of Clinical Endocrinology and Metabolism $2003 \mathbf{8 8}$ 4168-4174. (doi:10.1210/jc.2002-022040)

25 Quigley CA, Crowe BJ, Anglin DG \& Chipman JJ. Growth hormone and low dose estrogen in Turner syndrome: results of a United States multi-center trial to near-final height. Journal of Clinical Endocrinology and Metabolism 200287 2033-2041. (doi:10. $1210 /$ jc.87.5.2033)

26 Ranke MB, Partsch CJ, Lindberg A, Dorr HG, Bettendorf M, Hauffa BP, Schwarz HP, Mehls O, Sander S, Stahnke N, Steinkamp H, Said E \& Sippell W. Adult height after GH therapy in 188 Ullrich-Turner syndrome patients: results of the German IGLU Follow-up Study 2001. European Journal of Endocrinology 2002147 625-633. (doi:10.1530/eje.0.1470625)

27 Stephure DK. Impact of growth hormone supplementation on adult height in turner syndrome: results of the Canadian randomized controlled trial. Journal of Clinical Endocrinology and Metabolism 200590 3360-3366. (doi:10.1210/jc.2004-2187)

28 Chernausek SD, Attie KM, Cara JF, Rosenfeld RG \& Frane J. Growth hormone therapy of Turner syndrome: the impact of age of estrogen replacement on final height. Genentech, Inc., Collaborative Study Group. Journal of Clinical Endocrinology and Metabolism 200085 2439-2445. (doi:10.1210/jc.85.7.2439)

29 Reiter EO, Blethen SL, Baptista J \& Price L. Early initiation of growth hormone treatment allows age-appropriate estrogen use in Turner's syndrome. Journal of Clinical Endocrinology and Metabolism 200186 1936-1941. (doi:10.1210/jc.86.5.1936)

30 Hochberg Z \& Zadik Z. Final height in young women with Turner syndrome after GH therapy: an open controlled study. European Journal of Endocrinology 1999141 218-224. (doi:10.1530/eje.O. 1410218)

31 Sas TC, de Muinck Keizer-Schrama SM, Stijnen T, Aanstoot HJ \& Drop SL. Carbohydrate metabolism during long-term growth hormone $(\mathrm{GH})$ treatment and after discontinuation of $\mathrm{GH}$ treatment in girls with Turner syndrome participating in a randomized dose-response study. Dutch Advisory Group on Growth Hormone. Journal of Clinical Endocrinology and Metabolism 200085 769-775. (doi:10.1210/jc.85.2.769)

32 Radetti G, Pasquino B, Gottardi E, Boscolo Contadin I, Aimaretti G \& Rigon F. Insulin sensitivity in Turner's syndrome: influence of GH treatment. European Journal of Endocrinology 2004151 351-354. (doi:10.1530/eje.0.1510351)

33 Massa G, Bouillon R \& Vanderschueren-Lodeweyckx M. Serum growth hormone $(\mathrm{GH})$-binding protein and insulin-like growth factor-I levels in Turner's syndrome before and during treatment with recombinant human GH and ethinyl estradiol. Journal of Clinical Endocrinology and Metabolism $1992 \quad 75$ 1298-1302. (doi:10.1210/jc.75.5.1298)

Received 2 February 2011

Accepted 11 March 2011 